\title{
Mario Quintana na história literária sul-rio-grandense
}

p. $08-20$

Patrícia Vitória Mendes dos Santos Araújo ${ }^{1}$

André Luis Mitidieri ${ }^{2}$

João Claudio Arendt ${ }^{3}$

\section{Resumo}

A afirmação do nacionalismo literário e a busca por parâmetros europeus sempre foram elementos comuns na literatura produzida no território brasileiro. Durante o século XX, a literatura modernista mesclou, em diversos momentos, o local e o global, através da expressão europeia e da representação da narrativa nacional. No entanto, a década de 1940 parece presenciar um movimento contrário: o local é repudiado em favor de um desejo de generalização. Nesse contexto, o presente artigo busca verificar como algumas das histórias da literatura sul-rio-grandense, publicadas a partir da década de 1940, no momento em que Mario Quintana começa a editar seus livros de poesia, recebem a sua obra. Dentre as 20 obras analisadas, verificamos nove estudos de cunho biobibliográfico, histórico-literário ou monográfico, e 11 que se configuram como histórias da literatura sul-rio-grandense, sendo três delas focadas na poesia. De um total de 17 publicações que mencionam Quintana, a maioria concentra-se entre as décadas de 1970 e 1990, quando ele já obtém expressivo reconhecimento nacional.

Palavras-chave: História literária. Mario Quintana. Modernismo brasileiro. Literatura sul-rio-grandense.

\section{MARIO QUINTANA IN THE LITERARY HISTORY OF SOUTHERN BRAZILIAN LITERATURE}

\begin{abstract}
The affirmation of literary nationalism and European parameters have always been common elements in the literature produced in Brazil. During the twentieth century, modernist literature blended local and universal, through the European expression and the representation of national narrative. However, the 40s seems to witness a contrary movement: the local is rejected in favor of a desire to generalization. In this context, this paper aims to verify how some histories of sul-rio-grandense literature, published when Mario Quintana started to edit his poetry books, embrace his work. Among 20 works analyzed, we have found nine studies of biographical and bibliographical nature, besides historical, literary or monographic ones, and 11 works are histories of Rio Grande do Sul literature, three of them are focused on poetry.
\end{abstract}

1 Mestra em Letras: Linguagens e Representações pela Universidade Estadual de Santa Cruz, UESC, Brasil

2 Doutorado em Letras, área de concentração em Teoria da Literatura, pela Pontifícia Universidade Católica do Rio Grande do Sul (PUCRS). Pós-Doutorado em Estudos Literários pela Universidade Federal do Rio Grande do Sul (UFRGS). Coordenador e professor do Programa de Pós-Graduação em Letras - Mestrado em Linguagens e Representações - da UESC.

3 Doutor em Letras, professor do Programa de Pós-graduação em Letras da Universidade de Caxias do Sul - UCS - 
From an amount of 17 works that mention Quintana, most of them are concentrated between the 1970s and 1990s when he already had obtained significant national recognition. Keywords: Literary history. Mario Quintana. Brazilian Modernism. Sul-rio-grandense literature.

\section{Introdução}

Grande parcela das obras literárias produzidas em território brasileiro, segundo Antonio Candido (1980, p. 109), fiéis à "dialética do localismo e do cosmopolitismo", além de contaminadas por ideologias hegemônicas em distintos momentos, tendiam ora à afirmação do nacionalismo literário, ora às variadas formas de aproximação aos parâmetros europeus. Para esse crítico, no começo do século XX, "Os nossos modernistas se informaram pois rapidamente da arte europeia de vanguarda, aprenderam a psicanálise e plasmaram um tipo ao mesmo tempo local e universal de expressão, reencontrando a influência europeia por um mergulho no detalhe brasileiro" (CANDIDO, 1980, p. 121).

Depois de 1940, ainda na visão de Candido (1980, p. 126), a literatura brasileira pareceu presenciar certo repúdio ao elemento local e o retorno a um desejo de generalização que concebia a expressão literária como um problema de inteligência formal e resultante de pesquisa interior:

Até 1945, mais ou menos, vemos uma produção intensa, favorecida por grande surto editorial, em que brilham veteranos e novos, estes com tendência crescente para repudiar a literatura social e ideológica, o que veio finalmente a predominar sob a forma de uma queda da qualidade média do romance e uma grande voga de pesquisa formais e psicológicas na poesia. Entretanto, o abandono da linha modernista não se deu segundo os rumos previstos e propugnados pelos espiritualistas, - a saber, a atenção para o drama moral e o catolicismo poético. Os novos manifestaram pouco interesse pela literatura ideológica de esquerda e de direita, e os que tinham vocação política desleixaram não raro a literatura, passando diretamente à militância.

O Modernismo trouxe consigo uma concentração das escritas da história literária nacional no Sudeste brasileiro, o que se comprova, a título de exemplo, com as obras de Afrânio Coutinho (1968-1971), Alfredo Bosi (1997) e Antonio Candido (1959). Uma vez que a literatura restrita a essa região não se podia fazer portavOz da diversidade cultural do país, “as várias regiões e sub-regiões tenderam à autossuficiência ou à introversão: repelidas ou substituídas, ou simplesmente condenadas a situar-se em esfera secundária, tentaram bastar-se a si próprias, o que alimentou ainda mais o isolamento e agravou as discrepâncias de grau e densidade” (MOISÉS, 1984, p. 16). Com base nessa afirmação de Moisés, procuramos verificar se as várias das histórias da literatura sul-rio-grandense e trabalhos afins, publicados a partir da década de $1940,{ }^{4}$ quando Mario Quintana começava a editar seus livros de poesia, estabelecem uma recusa à obra do poeta devido ao fato de não se conjugar a uma suposta autossuficiência da produção literária estadual.

Essa questão já marcava, na década de 1940, o pensamento de intelectuais sul-rio-grandenses como Moysés Vellinho (1960, primeira edição em 1944) cujo estudo denominado Letras da Província,

\footnotetext{
4 Esse critério faz-nos excluir de nossas análises um texto de suma importância (SILVA, 1927), mas lançado quando recém Mario Quintana começava a publicar seus poemas em jornais e revistas, bem antes da primeira edição do seu primeiro livro: A rua dos cataventos (QUINTANA, 1940). Também deixamos de considerar duas obras de Ornellas (1938; 1966), porque esse "foi um entusiasta do Modernismo, na ocasião, tendo chegado mesmo a publicar um livro de versos, enquadrado nos princípios do verdeamarelismo, daí a falta de objetividade em muitas de suas informações” (LEITE, 1972, p. 25). Por motivo similar, eliminamos o artigo de Olyntho Sanmartin (1970) do corpus analítico, pois o ensaísta “[...] também é contemporâneo do Movimento, entretanto nunca foi muito entusiasta por ele e nega que tenha havido Modernismo no Rio Grande” (LEITE, 1972, p. 25).
} 
em vez de se relacionar a um desejo exacerbado de sentimento regionalista, tem a ver com a compreensão de que a imensidade do território brasileiro levaria o país a se constituir como um conjunto de províncias com peculiaridades que não comprometiam a unidade da nação, mas que pareciam primordiais à manutenção de sua vitalidade. Na perspectiva de Vellinho, apesar de se caracterizar como um dos estados brasileiros mais aferrados às suas particularidades, o Rio Grande do Sul teria sido sempre fiel ao ideal comunitário, por exemplo, nas produções literárias de Alcides Maya, Athos Damasceno Ferreira, Augusto Meyer, Dionélio Machado, Erico Verissimo, João Pinto da Silva e Vianna Moog.

Elenco similar figura em Elementos para uma bibliografia sobre o Rio Grande do Sul, no qual Francisco Ferreira [1950?] cita o nome de Quintana, mas nada afirma sobre ele. Já no ensaio "Condições histórico-sociais da literatura rio-grandense", publicado na revista Província de São Pedro, e no qual o poeta em destaque não é mencionado, Carlos Dante de Moraes (1954, p. 7-18) mostra que, assim como ocorreu em quase toda a literatura brasileira, a produção literária sul-rio-grandense entre os anos de 1920 e 1930 registrava expressões críticas, ensaísticas ou líricas. Sobre as duas décadas seguintes, afirma:

\footnotetext{
A geração moça parece quase toda ela voltada com ardor para a universalidade. Tais jovens entram na existência numa época atormentada de problemas cruciantes, não somente sociais, mas também filosóficos e metafísicos. Tudo os leva à inquirição, à procura, ao debate. Ou, então, buscam na anotação lírica das suas emoções tumultuosas a primeira maneira de se afirmar. É uma geração que se exprime principalmente na poesia, na crítica ou na autocrítica. De certo modo, reata-se a curva ascendente do modernismo em sua fase aguda. Já não existe, porém, a euforia estética daquela hora feliz e aventurosa. Agora, as experiências e os problemas assumem aspectos mais graves, mais prementes e dramáticos (MORAES, 1954, p. 17-18).
}

Ultrapassar questões estritas do regionalismo e da nacionalidade na história literária brasileira, segundo José Luis Jobim (1992), é tarefa árdua para alguns críticos literários e historiadores da literatura, os quais podem se declarar impossibilitados de "descalçar os próprios sapatos", de se tornarem "diferentes do que efetivamente são" ou de recorrer a outras expressões capazes de justificar que continuem limitados aos seus modos de conhecimento:

Explicariam, assim, a sua permanência no
círculo das significações perigosamente
comuns, que compõem a 'tradição' deles.
Contudo, estes historiadores e críticos
poderão também vir a suspeitar que estes
'sapatos' e esta 'maneira de ser' não são os
únicos possíveis. A suspeita talvez evite que,
arrogantemente, tentem impor sua sombra
às margens do vulto que projetam. Ou talvez
implique eles se imaginarem os artífices da
construção de seu próprio vulto, com uma
reserva incalculável de sombra (JOBIM,
1992, p. 146).

Não seria esse o caso de Augusto Meyer (1965) que, no capítulo "O fenômeno Quintana” (p. 157-160), do livro A forma secreta, nota certa convivência e competição entre Parnasianismo e Simbolismo no Rio Grande do Sul, durante os anos posteriores à Semana da Arte Moderna de 1922. Dentre os poetas lidos no estado, avultariam Apollinaire, Aragon, Cendras, Ealmon, Folgore, Govoni, Max Jacob, Palazzeschi e Manuel Bandeira, especialmente, o seu livro Ritmo dissoluto. De outro lado, a "febre nativista" ou brasileira, que "[...] de algum modo já existia no Rio Grande, com o renovo do nosso Regionalismo, num sentido muito restrito, convencional às vezes, decerto não condizendo com o espírito da nova cruzada. Não quer dizer isto que o modernismo gaúcho resultou de uma simples transformação do Regionalismo; creio que houve coincidência de motivos, convergência de propósitos” (MEYER, 1965, p. 158). 
Ao tempo em que faltava uma poesia distante dos modelos tradicionais, mais ampla, direta, livre, subjetiva, despontava Mario Quintana com "[...] a autenticidade, a cristalinidade da sua arte [...]. Não sei de outro poeta em que o poema seja uma consubstanciação tão perfeita entre viver e cantar, entre sofrer vivendo e sofrer cantando. Ele é, dando luz na corrida a todos, o maior poeta moderno do Rio Grande" (MEYER, 1965, p. 159). Lígia Chiappini Moraes Leite (1972) aborda esse contexto em Modernismo no Rio Grande do Sul: materiais para o seu estudo, detendo-se primeiramente na centralização do referido movimento em São Paulo e no Rio de Janeiro, fato reiterado por compêndios literários que consideram ínfima sua repercussão no estado sulino. Muitos intelectuais negam sua existência nesse espaço, onde, contudo, ressaltam as expressões modernistas de Dyonélio Machado, Erico Verissimo, Mario Quintana e Raul Bopp.

A autora destaca Quintana como uma das figuras mais originais no período, justamente por não se enquadrar no modernismo enquanto escola literária brasileira, ainda que contribua para com o aumento da liberdade formal e a quebra da distinção entre motivos poéticos e não poéticos. Moraes Leite (1972) também ressalta a declaração do escritor acerca de um possível vínculo com a cultura tradicional gaúcha, quando declarou que " $[. .$.$] a poesia quanto mais individual, mais$ universal' 'Sou um gaúcho sentado, o que me afasta da tradição" (LEITE, 1972, p. 243). Por outro lado, "assinava revistas e lia os livros e revistas estrangeiras na Biblioteca Pública, principalmente na época em que Eduardo Guimarães era o seu diretor. Lia muito Dostoievski, os simbolistas, 'tinha mania por Apollinaire' [...]”' (LEITE, 1972, p. 243-244).

Essa questão ocupa o eixo central do ensaio $O$ regional e o universal na literatura gaúcha, em que José Clemente Pozenato (1974, p 15) considera o regionalismo como um conceito de largo espectro significativo, portador de ambiguidades, impreciso e sem estatuto literário definido, referindo-se ora à representação de uma realidade regional numa obra literária, ora à intenção de realizar essa representação. O que se verifica, no primeiro caso, é a presença do elemento local em qualquer obra literária, reconhecida como de caráter universal, sempre situada em relação a um lugar, real ou imaginário, e datada no que respeita a um tempo, igualmente real ou imaginário. Segundo o autor, no Rio Grande do Sul, como no Brasil, constata-se a presença regionalista nos movimentos romântico, realista e modernista, sendo que, nesse último, "Mario Quintana é, a rigor, o primeiro poeta gaúcho a fazer lirismo urbano, onde se sente o estigma da vida citadina da província” (POZENATO, 1974, p. 39).

Para além da expressão regional, Nelson da Lenita Fachinelli (1976) é o primeiro que, em publicação monográfica e biobibliográfica lançada no âmbito estadual, refere-se a Quintana como "[...] um dos melhores poetas do nosso Brasil. É isto que pensa quem gosta dele como um irmão, um tal de Erico Veríssimo". Por seu turno, Antonio Hohlfeldt (1978), em Antologia da literatura rio-grandense contemporânea, comenta que a crítica literária tem papel importante na década de 1960, por trazer a lume em jornais, obras inéditas de autores pouco conhecidos, dentre os quais, Lara de Lemos e Lilla Ripoll, de importância ímpar no que concerne à poesia. Ao mencionar Raul Bopp e Quintana, considera que esse, juntamente com Carlos Drummond de Andrade, é um dos maiores poetas brasileiros ainda vivos.

O escritor nascido na cidade de Alegrete, todavia, não faz parte de Poesia modernista no Rio Grande do Sul, esboço de um panorama da produção poética gaúcha durante o século XX no qual Donaldo Schüler (1982) destaca os seguintes escritores e suas obras: Athos Damasceno 
Ferreira, Augusto Meyer, Ernâni Fornari, Felipe de Oliveira, Guilhermino César, Manoelito de Ornelas, Olmiro Azevedo, Raul Bopp, Ruy Cirne Lima, Theodomiro Tostes, Tirteu Rocha Viana e Vargas Neto.

O mesmo objetivo de fornecer um elenco de destacados autores do estado norteia Quem é quem nas letras rio-grandenses, dicionário no qual Blásio Hickmann e Sérgio Faraco (1983, p. 196) dedicam nove páginas a Mario Quintana, depois de apresentá-lo com uma nota de abertura: “Jornalista, emérito tradutor, é o grande poeta rio-grandense de todos os tempos, que o Brasil, embora tardiamente, sempre descobriu e aprendeu a amar. Traduzido em diversos países e granjeando um número progressivo de leitores de todas as idades, sua poesia, hoje é um patrimônio da literatura universal".

Sob prisma semelhante, no livro $A$ literatura no Rio Grande do Sul: aspectos temáticos e estéticos, Luiz Marobin (1985, p. 205) trata Quintana como "poeta das belas imagens", salientando a individualidade e a universalidade como características fundamentais desse “[...] que é profeta e anjo em sua própria terra - o Alegrete e Porto Alegre", mas igualmente "[...] reconhecido e estimado em todo o Brasil".

Por sua vez, em Literatura gaúcha: temas e figuras da ficção e da poesia do Rio Grande do Sul, Regina Zilberman (1985, p. 117-118) destaca:

A geração modernista, que se impõe aqui depois de 1925, tendo entre seus membros Augusto Meyer, Theodomiro Tostes, Athos Damasceno Ferreira, Reynaldo Moura, Mario Quintana, revela ter-se abeberado, durante sua formação, na poética simbolista, que nunca abandona seus versos. Pela mesma razão, dá continuidade à perspectiva existencial que a impede de incorporar passivamente valores domésticos, próprios à visão de mundo burguesa. Porém, mostra-se mais coerente, de um lado, por rejeitar a rotina de modo integral, de outro, por defender, sem preconceitos ou sentimento de inferioridade, sua natureza sui generis de artista e assumir os riscos que a atividade criadora carreia consigo.

Segundo a mesma estudiosa, nos textos modernistas do Rio Grande do Sul, não se encontram nem a temática engajada nem a espécie de apostolado que se detecta nos autores românticos e realistas, mas um componente anárquico revelado, por exemplo, no poema Cobra Norato (1931), de Raul Bopp, e nos quartetos escritos por Mario Quintana desde a década de 1930, reunidos e publicados em Espelho mágico apenas no ano de 1951. Isso transparece tanto no deslocamento aventureiro do protagonista de Bopp pela Amazônia, na pele de uma cobra d'água, quanto no individualismo de uns, em especial de Quintana, o menos alinhado dos poetas gaúchos, que fez questão

de acentuar a independência de sua poética, recusando-se a frequentar qualquer escola literária [...] não significam a produção de uma literatura escapista ou egocêntrica. Pelo contrário, estas opções representam a afirmação da identidade pessoal perante a massificação, reagindo ao avanço nivelador da sociedade industrial [...] (ZILBERMAN, 1985, p. 118).

No entanto, o escapismo não estaria fora do horizonte do poeta, conforme Donaldo Schüler (1987) que, em outra obra, intitulada $A$ poesia no Rio Grande do Sul, assim se posiciona a seu respeito:

A evasão abriu a Quintana a distância necessária à observação continuada. Por não se comprometer, pode observar atentamente e detectar fraturas proibidas a comportamento apaixonado. Mario Quintana conserva-se na tradição sem resvalar para o tradicionalismo. $\mathrm{O}$ tradicionalismo enreda os seus cultores nas malhas do passado, bloqueando opções originais. $O$ conservar-se na tradição permite avaliar as respostas dadas sem 
comprometer-se com elas, reativando o vigor que as fez nascer. Em Mario Quintana, convergem as linhas e se abrem em leque renovadas (SCHÜLER, 1987, p. 238).

Por sua vez, no capítulo "As duas faces do emparedamento: Mario Quintana e Aureliano de Figueiredo Pinto", do livro Um passado pela frente: poesia gaúcha ontem e hoje, Luís Augusto Fischer (1992, p. 79) apresenta o universo da criação poética sul-rio-grandense como assinalado por:

[...] uma obrigação localista, espécie de tarefa construtiva inescapável inventada pela herança histórica, e um horizonte de referências balizado pelo andamento das correntes estéticas já estabelecidas ou recém-propostas. Os poemas ora mostrarão atender à demanda particular, ora quererão ajustar-se ao momento geral, mas em todos os casos terão em vista as duas mãos desse fluxo.

Mais adiante, a análise do ensaísta atinge tanto a poesia gaúcha em toda a sua extensão e recepção quanto as obras de dois dos seus já consagrados representantes:

Foi por não sabermos o que fazer com a herança guerreira, e sentirmo-nos no entanto condenados a ela, que preferimos Casimiro a Castro Alves, o lírico ao épico. Da mesma forma, foi por isso que não produzimos, em regra, poesia moderna: não ouvimos (aliás renegamos, pela pena de Quintana) o ensinamento de Baudelaire, ou o exemplo de Augusto dos Anjos; menos ainda aceitamos a lição degradada da poesia que se deixou contaminar até as entranhas pela consciência cética sobre as possibilidades de enunciar o mundo - Eliot, Fernando Pessoa, Drummond, digamos. Não estranha, pois, que nossos dois melhores poetas - considerando a consistência quantitativa e qualitativa de suas obras, o grau de influência exercida e a exemplaridade de seu trabalho no sentido de concentrar e realizar esteticamente tendências esparsas da alma gaúcha - sejam dois românticos de feição casimiriana, atentos ao registro lírico dos temas muito mais que à atitude épica diante deles (e muito menos questionadora: Mario Quintana e Aureliano de Figueiredo Pinto, este dedicando-se ao tema regional, aquele a temas da vida urbana e à infância (FISCHER, 1992, p. 84-85, grifo nosso).

A modernidade negada ao poeta de Alegrete, no ensaio de Fischer (1992), é contraditada pela obra A literatura no Rio Grande do Sul, lançada no mesmo ano por Regina Zilberman (1992a), a qual tem um de seus capítulos intitulado "O modernismo e a poesia de Mario Quintana" (p. 61-74). A autora sublinha ser esse poeta quem, no cenário local, leva adiante a experiência modernista:

\footnotetext{
Evitando dois assuntos bastante frequentados pelos poetas modernistas, quais sejam, a reflexão sobre o lugar do homem no mundo e na sociedade, como fazem Cassiano Ricardo e Carlos Drummond de Andrade, e a expressão religiosa, própria a Jorge de Lima e Murilo Mendes, Quintana explora antes uma linha provocativamente individualista (ZILBERMAN, 1992a, p. 69).
}

Em vez da denúncia ao desequilíbrio social, a poética quintaniana prefere a lamentação, também moderna, da transitoriedade da vida e do homem. Além de revelar a intranquilidade e o desconforto próprios ao Simbolismo, do qual a poesia gaúcha somente se aparta depois da década de 1950 (Cf. ZILBERMAN, 1992a, p. 74), Quintana permite inferir que, a despeito de sua temática individualista, não andava sozinho a ponto de se tornar, "[...] nos limites do estado uma espécie de totem, e nos limites do país a referência praticamente única da poesia gaúcha" (FISCHER, 1992, p. 91).

Regina Zilberman (1992b, p. 21) assinala, em Roteiro de uma literatura singular, que Mario Quintana, juntamente com Paulo Correa Lopes e Lila Ripoll, "[...] preferiu compartilhar o intimismo herdado dos simbolistas". Já nos 
Painéis da literatura gaúcha, Luiz Marobin (1995, p. 20) dispõe o primeiro desses poetas em companhia de Armindo Trevisan e Carlos Nejar, como exemplos da "temática ascensional", plano que uniria o regional e o universal na poesia sul-rio-grandense. Considerado o lírico gaúcho verdadeiramente modernista por Francisco Bernardi (1997, p. 55), em As bases da literatura riograndense, Bopp e uma parte da obra de Augusto Meyer contariam entre as únicas exceções locais que se somariam ao conteúdo temático e filosófico do modernismo observado no restante do país. Sobre Quintana, considera que "nunca se preocupou com a estética modernista, com o nacionalismo, com o gauchismo (regionalismo), com a modernidade, em suma".

Entretanto, Zilberman (1992b, p. 21) afirma que esse poeta se identifica com uma experiência modernista distante da ruptura própria ao futurismo, assim como ela seria herdeira do individualismo e da preocupação com a forma, típica do Simbolismo e do Parnasianismo que, no Brasil, não trilhavam rumos muito diferenciados:

Poesias, obra em que reúne a produção dos anos 40, expressa suas preocupações mais candentes: o respeito a um princípio formal de composição; e a manifestação do eu lírico, cuja natureza especial, à margem das convenções da sociedade, defende a qualquer preço. Este individualismo reaparece nos livros da década de 70, como Apontamentos de história sobrenatural, e ainda caracteriza na poesia mais recente, no seu percurso de octogenário .

Portanto, o autor d'A rua dos cataventos não suportaria o traço que lhe atribui Fischer (1992, p. 93): "uma carga de romantismo evidente (entre nós, veja-se o poema 'Ahasverus e o gênio', de Castro Alves, ou, noutro sentido, de antiformalismo); ao poeta repulsa desde sempre qualquer tendência poética cujo epicentro seja a forma”. Em afastamento à ideia de que Quintana possa rejeitar "[...] um dos vetores radicais da modernidade poética - a especulação dos limites da forma" (FISCHER, 1992, p. 93), Guilhermino César (1994, p 147), em Notícia do Rio Grande: literatura, infere que a liberdade formal da poesia quintaniana cria realidade sonora própria:

\footnotetext{
Aliás, a poesia de Mario Quintana, em sua fase atual, tende a superar, e tem alcançado isso em muitos momentos, a musicalidade que encontrou feita. No princípio de sua admirável trajetória de poeta, ele se prendia bastante, no concernente ao ritmo, a certos bons poetas simbolistas e parnasianos europeus. Hoje, em plena maturidade artística, sua poesia tem uma nota pessoal inconfundível; pelo ritmo, precisamente, é uma das mais finas, das mais sábias da língua portuguesa. Para certos ouvidos duros à translinguagem lírica, a leveza dos quintanares pode parecer uma concessão ao 'fácil'. Que engano! Quintana é o contrário do poeta bem comportado, em matéria de ritmo. A surdina, no que escreve, é uma feição própria do homem \& do artista. Repito: do homem \& do artista. Os dois formam uma combinação em que diviso, antes de tudo, o pudor de ser.
}

Enquanto Guilhermino César (1994, p. 147) crê que a poesia quintaniana e seu próprio sujeito produtor se fundem com os objetos e os seres vivos dos quais falam, Fischer (1992, p. 94) assevera que essa fusão entre a vida vivida e a lírica assinalaria "uma poética antirracionalista, que se felicita por perder o assunto (que jamais existiu) e, por afinal, consumar um desejo latente de imiscuir-se na paisagem". Esse mesmo estudioso que compreende a obra de Quintana como "solidária com a vida e afastada dos tormentos modernos: poesia compreendida como lição de vida, depoimento de experiência, e não artefato, construção, nem mesmo o torturado fingimento definido por Fernando Pessoa na "Autopsicografia" (FISCHER, 1992, p. 95), na página anterior do mesmo ensaio, ele alerta para seus "momentos mais radicais de 
indagação, que, se não chegam a problematizar o trabalho poético a ponto de fazer perder a fé nas palavras e na formulação escrita do mundo, certamente estabelecem sua poética num plano nosso contemporâneo" (FISCHER, 1992, p. 94).

Afinado com a primeira de tais posturas, como visto, Bernardi (1997, p. 55) ressalta que o poeta de Alegrete não demonstrou preocupações nem com a modernidade, nem com o modernismo. Sua obra estaria situada no mundo onírico, e do mistério que se une ao humor espontâneo, voltado ao cotidiano:

A cidade de seus poemas foi Porto Alegre, porque se tornou porto-alegrense, assim como poderia ter se tornado paulistano ou parisiense. Vai captando os detalhes do ambiente, da vida das pessoas, numa postura contemplativa própria dos impressionistas, o que o aproxima do Simbolismo. Com efeito, sua poesia frequentemente se vale de sinestesias, de entretons, de musicalidade.

Em outro livro de sua autoria, denominado Literatura gaúcha, Fischer (2004) discorre acerca da produção literária modernista, afirmando que se tornou comum eleger como parâmetro as obras literárias apresentadas na Semana de Arte Moderna de São Paulo, principalmente, as de Mário e Oswald de Andrade. Por esse prisma, seriam desconsideradas produções sulrio-grandenses que não seguiram totalmente os padrões propostos pelos artistas paulistas e cariocas, pois o modernismo gaúcho, “[...] por vários motivos (que incluem o temperamento da cultura local, mais próximo do estilo hispanoamericano de ver as coisas) foi um desdobramento do Simbolismo" (FISCHER, 2004, p. 75).

Para o estudioso, no livro de estreia de Quintana - A rua dos cataventos-, já se localizariam as temáticas dominantes de sua obra, como o desconsolo com o tempo presente e com a cidade grande, a busca de lugares utópicos que compensem a degradação da vida, "o domínio altíssimo dos meios expressivos colocados a serviço de uma visão ora simbolista, em parte meditativa, em parte ainda brandamente surrealista" (FISCHER, 2004, p. 94). Em Do Caderno $\mathrm{H}$, o poeta

\begin{abstract}
revelou-se um coração romântico, que recusava os debates apresentados pelo mundo contemporâneo - e talvez essa recusa seja um marco geral da limitação de seu alcance: na hora em que o mundo se via metido na Segunda Guerra, em chacinas como as dos campos de concentração, na Guerra Fria, etc., Quintana tomava a palavra para dizer, ativamente, que sua poesia (e toda a verdadeira poesia, em sua opinião) não tinha nada a ver com aquilo. Claro, é de desejável e impostergável liberdade do artista que ele tenha essa opinião; o ponto é que talvez justamente essa atitude, se lhe levou a lírica a locais elegantes, expressando uma visão de certa forma passadista do mundo, cobrou-lhe talvez um alto preço, o de permanecer à margem (FISCHER, 2004, p. 94-95).
\end{abstract}

Nos trabalhos sobre a literatura gaúcha que Fischer (1992; 2004) publica, com intervalo de pouco mais de uma década, o passado aparecelhe como elemento incômodo na obra de Mario Quintana, ora apreciada como antiestética, antiformalista, antimoderna, antirracionalista e passadista, ora como "depoimento da experiência", "refém da herança histórica" ou "romântica de feição casimiriana". Por outra via, Zilberman (1985) situa a poética às vezes anárquica de Quintana nos tempos modernos, como reação à sociedade industrial massificada, enquanto Schüler (1987, p. 229-238) avalia que a originalidade do poeta consiste em revigorar crítica e criativamente a tradição, sem que essa, contudo, imponha limites a uma diversidade de tendências que individualiza em sua poética.

Além de conciliar, em Pé de pilão, “[...] suas qualidades de miniaturista às de narrador" (SCHÜLER, 1987, p. 237), n'A rua dos cataventos, o poeta evoca os tempos de criança, em 
simplicidade que "[...] lembra Casemiro de Abreu, com frequência elogiosamente citado por Quintana. Esta tendência o conecta com a linhagem dos casimiristas, que na observação de Guilhermino César atuaram no Rio Grande do Sul antes mesmo de Casimiro. Mario Quintana recupera esta tradição contra a poesia heroica e laudatória por ele condenada" (SCHÜLER, 1987, p. 236). O mesmo crítico ainda dá ciência de traços que caracterizam a poesia quintaniana posterior aos livros citados:

\begin{abstract}
A poesia pura tivemos em Canções e Aprendiz de feiticeiro. A poesia de reflexão teórica enche Espelho mágico, inaugurando um grupo a que se filiam os últimos livros de Quintana; tanto em prosa, Caderno $H, A$ vaca e o hipogrifo, como em versos, Apontamentos de história sobrenatural, Esconderijos do tempo. As reflexões teóricas não pretendem armarse em sistema. Espelho mágico mostrouse, ao contrário, demolidor de sistemas. Dois títulos apontam para o assistemático: Caderno, Apontamentos. As reflexões aparecem assentadas ao acaso das evocações e das sugestões de leitura. Muitas delas na sua concentração oferecem o vigor da literatura epigramática. Cobrem preferencialmente dois campos: teoria literária e filosófica. Não se busquem nas reflexões pensamento originial. Nem Quintana tem pretensão de originalidade (SCHÜLER, 1987, p. 236).
\end{abstract}

Não seria muito distinto o posicionamento de Moraes Leite (1972) quando sublinha, nos textos quintanianos, certa libertação formal e temática, nesse último caso, ao problematizar a distinção entre o que seria ou não matéria de poesia. Essa liberdade da forma, ressaltada por César (1994), tipifica a obra de Quintana como modernista, conforme explicitam Bernardi (1997) e Zilberman (1992a; 1992b). Muito além de um pouco provável antimodernismo, embora se vincule, de alguma maneira, ao Parnasianismo e ao Simbolismo (Cf. ZILBERMAN, 1992b, p. 21), o escritor delimita o círculo de atuação do Modernismo gaúcho: “[...] ainda está dentro dele, porque simpatizante da nostalgia simbolista, o que sugere o passadismo do movimento em nosso meio e sua relativa importância no conjunto da literatura brasileira" (ZILBERMAN, 1992a, p. 74).

Além de situar-se na configuração regional do modernismo, afastando-se, portanto, de uma corrente preponderante na literatura brasileira, o poeta tampouco deixaria de se vincular, de alguma forma, à tradição literária do seu estado:

Em Mario Quintana, confluem várias correntes da poesia rio-grandense. O dizer singelo dirigido à captação do cotidiano revigora o texto arcaico. $\mathrm{O}$ ironista, demolidor de sistemas, recolhe as farpas de Amaro Juvenal. O pensador navega cético no mar de ideias que inunda o estado desde a Guerra dos Farrapos. O experimentalista prolonga os inventos já frequentes no princípio do século. O narrador mantém viva a poesia narrativa (SCHÜLER, 1987, p. 238).

Dentre os 20 trabalhos aqui consultados nove estudos de cunho biobibliográfico, históricoliterário ou monográfico, e 11 obras consideradas especificamente histórias da literatura sul-riograndense, sendo três delas focadas na poesia (SCHÜLER, 1982; 1987; FISCHER, 1992) -, apenas três não citam Mario Quintana: Vellinho (1960 [1944]); Moraes (1954) e Schüler (1982). O segundo desses ensaístas destaca que o problema dos escritores sul-rio-grandenses na década de 1950 dizia respeito a suas preocupações com o universalismo, ainda que a tradição gaúcha diferisse do modernismo praticado no eixo RioSão Paulo e esse, dos padrões universais da escola modernista.

De um total de 17 publicações que mencionam Quintana, a maioria concentra-se entre as décadas de 1970 e 1990, quando ele já possui expressivo reconhecimento nacional. Dentre elas, apenas a de Ferreira [1950?] não tece comentários a seu respeito, ao passo que Moraes Leite (1972) ressalta o fato de o poeta não se 
encaixar no modernismo considerado enquanto movimento da literatura brasileira. Meyer (1965) ainda o trata como um poeta do Rio Grande do Sul, enquanto Fachinelli (1976) e Hohlfeldt (1978) já o inserem entre os melhores poetas brasileiros, assim como Hickmann e Faraco (1983), que também não deixam de ressaltar sua pertença ao panorama literário do estado sulino, tal qual mais tarde o fazem Fischer (1992) e Zilberman (1992a).

A contraposição localismo $\mathrm{x}$ cosmopolitismo, conforme detectada por Candido em 1965, sobressai ou está implícita nas avaliações da poética quintaniana realizadas mais tarde por Moraes Leite (1972), Pozenato (1974), Marobin (1985; 1995); Schüler (1987), Bernardi (1997) e Fischer (1992; 2004). Marobin (1985), Schüler (1987) e César (1994) detectam nela determinada individualidade que, para o primeiro, ombreia com a universalidade; para o segundo, faz com que não saia da tradição sem, contudo, deslizar ao tradicionalismo; para o terceiro, expressa-se em liberdade formal. $\mathrm{Na}$ visão de Zilberman (1985), as marcas individuais e a recusa em aderir a movimentos literários permitem a Quintana superar qualquer tipo de questões relativas ao tensionamento entre o regional e o universal. Em estudos posteriores, Zilberman (1992a; 1992b) confirma e amplia essa tese, a partir do momento em que tributa a sua dicção individualista um ponto de corte em referência aos modernistas do Sudeste brasileiro, mas, ao mesmo tempo, um viés de concomitante inserção no Simbolismo e ao Modernismo, em proximidade que teria assinalado a lírica sul-riograndense entre as décadas de 1920 e 1950 e a obra do poeta alegretense em seu conjunto.

A presente investigação permite concluir que instrumentos da pesquisa de caráter históricoliterário não vêm sendo relegados pela crítica brasileira nem no século XX, nem a princípios do século XXI. Muitas histórias da literatura ou materiais contíguos que estudamos demonstram certa mistura entre os horizontes da crítica e da historiografia literária, bem como o domínio da crítica universitária entre as publicações de teor histórico-literário. No percurso da pesquisa, notamos que a história literária sul-rio-grandense raras vezes escapa da submissão a uma estética hegemônica em determinados tempos. Desse modo, a obra de Mario Quintana, nos diferentes estudos analisados, tem no Modernismo um ponto fulcral, quando comparada em afastamento dessa escola ou em aproximação a ela.

Nesse polo, situa-se Fischer (1992; 2004) quando tributa ao poeta de Alegrete uma suposta inabilidade para elaborar artefatos de extrema originalidade e sofisticação ou quando the impinge rótulos de casimiriano e passadista. O estudioso sintoniza, pois com a "estética da terra arrasada":

Ela é o princípio do Modernismo, como a expressão de um dos seus maiores expoentes: T. S. Eliot. A euforia otimista do final do século, a belle époque, é substituída pelo desencanto de depois da I Guerra Mundial. Para Otto Maria Carpeaux, 'esse pessimismo estava no ar quando Eliot escreveu The Waste Land [1922]. A guerra deixara a impressão duma catástrofe profundamente desmoralizada e muita gente preferiu, como mais verdadeira, a visão duma corrida para o fim'. Carpeaux caracteriza o poeta norte-americano de reacionário, portanto, excluindo o fim de suas pretensões. Isso significa que o Modernismo também não deixa de ser, pelo poema emblemático, expressão da passagem temporal, Modernidade, e literária, Modernismo, pelo efeito da acidez do arrasamento da terra. Há, no dizer do autor de Livros na mesa, uma orientação pela manutenção dos grandes códigos e cânones como saída para o desencanto e para o arrasamento moral similar à obscena imitação da paisagem lunar a partir da edificação das incontáveis crateras em solo rural e urbano, como efeito de bombardeios. Nesse sentido, da passagem do otimismo para o pessimismo na inauguração do século XX, forja-se a 
tradição da ruptura. Expressões intelectuais eufóricas e depressivas sempre aparecem na cena da cultura do Ocidente, então, o interesse volta-se para a banalização das duas estéticas e filosofias. Octavio Paz, ao questionar o modelo de poesia moderna na tradição sempre em falso, acaba produzindo o esquema da Modernidade: 'Se a ruptura é destruição do vínculo que nos une ao passado', tradição, agora, é a destruição de um modelo de escola literária para que outro tome seu lugar vigorosamente. O modelo previa o primeiro passo de destruição e um segundo, de remoção dos detritos (PINHO, 2008, p. 30-31).

Trilhando caminho menos faccioso, Fausto Cunha (1964) procura entender as incompletudes e os meandros daquela que considera uma poesia difícil. Em apreciação, cuja perspectiva crítica afasta-se deste corpus formado por histórias da literatura e estudos similares, Cunha assim dirige sua visada a Mario Quintana: "Um poeta quase 'passadista' repentinamente inscreve seus versos ao lado da belíssima canção dos astronautas russos (que diz: 'Não, não está muito longe o mais longínquo planeta!') e dos poemas neogóticos de Heinlein e de Bradbury: 'Vamos! vamos lançar no espaço - alto, cada vez mais alto! A rede das estrelas"” (CUNHA, 1964, p. 158, grifo nosso).

A articulação observada por Zilberman (1992a; 1992b) entre Modernismo, Simbolismo e literatura gaúcha permite contrariar ideias expressas por Candido - tanto a lógica binária (localismo x cosmopolitismo), quanto a refutação ao elemento local (observada na literatura nacional pós-1940). No momento em que a mesma autora não subtrai a Quintana uma digital modernista bastante individualizada, também nos permite o desprendimento de vícios críticos, dentre eles, aquele que o toma por neossimbolista ou romântico fora de seu tempo, embora não se esquive de sublinhar os tons passadistas do movimento modernista no Rio Grande do Sul. Neste caso particular, o acercamento aos padrões europeus e os elementos locais das escritas deslocadas do eixo através do qual se estabelecia a modernização periférica brasileira davam forma a normas e desvios que, sem se identificarem estritamente com as dominâncias estéticas nacionais, tampouco se limitavam às balizas de um regionalismo cujos cenários, temas e vocabulário pudessem limitar sua recepção.

É desse modo que o "anjo-poeta” não se restringe às margens da modernidade literária, dentro das quais também não fica circunscrita a literatura do seu estado que, não só com ele, mas a lhe dever "pesada moeda", pôde evitar pretensões de autossuficiência, sem que fosse substituída, repelida ou confinada em uma esfera secundária. Em última análise, embora a história literária sulrio-grandense raras vezes escape da submissão a uma estética hegemônica em determinados tempos, a poética de Quintana ultrapassa a lógica binária pressuposta pela dialética localismo $\mathrm{x}$ cosmopolitismo. Sua proximidade aos padrões europeus e aos elementos locais de uma escrita deslocada do eixo Rio-São Paulo desvia-se de uma compreensão regionalista em sentido estrito.

\section{Referências}

BERNARDI, F. As bases da literatura riograndense. Porto Alegre: AGE, 1997.

BOSI, A. História concisa da literatura brasileira. 3. ed. 17. tiragem. São Paulo: Cultrix, 1997 [1970].

CANDIDO, A. Formação da literatura brasileira: momentos decisivos. 2. ed São Paulo: Martins, 1959. 2. v.

CANDIDO, A. Literatura e sociedade. 6. ed. São Paulo: Companhia Editora Nacional, 1980 [1965).

CÉSAR, G. Notícia do Rio Grande: literatura. Porto Alegre: Instituto Estadual do Livro; EdUFRGS, 1994. 
COUTINHO, A. (Org.). A literatura no Brasil.

7. ed. Segunda edição da obra completa publicada entre 1968-1971. Rev. amp. 1986 sob a codireção de Eduardo de Faria Coutinho São Paulo: Global, 2004. $6 \mathrm{v}$.

CUNHA, F. A luta literária. Rio de Janeiro: Lidador, 1964.

FACHINELLI, N. da L. Mario Quintana, vida e obra. Porto Alegre: Bels, 1976.

FERREIRA, J. F. Elementos para uma bibliografia sobre o Rio Grande do Sul. [S.l.]: [S.n.], [1950?].

FISCHER, L. A. Literatura gaúcha. Porto Alegre: Leitura XXI, 2004.

FISCHER, L. A. Um passado pela frente: poesia gaúcha ontem e hoje. Porto Alegre: Editora da Universidade; UFRGS, 1992.

HICKMANN, B.; FARACO, S. Quem é quem nas letras rio-grandenses. Porto Alegre: Divisão de Cultura, 1982.

HOHLFELDT, A. Antologia da literatura rio-grandense contemporânea. Porto Alegre: L\&PM, 1978.

JOBIM, J. L. História da literatura. In: JOBIM, J. L. (Org). Palavras da crítica. Rio de Janeiro: Imago, 1992, p. 127-149.

LEITE, L. C. M. Modernismo no Rio Grande do Sul: materiais para o seu estudo. São Paulo: Instituto de Estudos Brasileiros, 1972.

MAROBIN, L. A literatura no Rio Grande do Sul: aspectos temáticos e estéticos. Porto Alegre, Martins Livreiro, 1985.

MAROBIN, L. Painéis da literatura gaúcha. São Leopoldo: Editora da UNISINOS, 1995.

MEYER, A. O fenômeno Quintana. In: MEYER, A. A forma secreta. Rio de Janeiro: Lidador, 1965, p. 157-160.
MOISÉS, M. História da literatura brasileira. São Paulo: Cultrix, 1984. 5 v. v. 1 (Das origens ao Romantismo).

MORAES, C. D. d. Condições histórico-sociais da literatura rio-grandense. Província de São Pedro, Porto Alegre, p. 7-18, 1954.

ORNELLAS, M. d. Máscaras e murais de minha terra. Porto Alegre: Globo, 1966.

ORNELLAS, M d. Vozes de Ariel. Porto Alegre: Globo, 1938.

PINHO, A. M. Uma história da literatura de jornal: O Imparcial da Bahia. 2008. 404 f. Tese (Doutorado em Letras). Instituto de Letras e Artes, Pontifícia Universidade Católica do Rio Grande do Sul, Porto Alegre (RS), 2008. 3v. v. 1.

POZENATO, J. C. O regional e o universal na literatura gaúcha. Porto Alegre: Movimento, 1974.

SANMARTIN, O. O modernismo na literatura rio-grandense. Correio do Povo, Porto Alegre, 15 ago. 1970.

SCHÜLER, D. Poesia modernista no Rio Grande do Sul. Porto Alegre: Movimento, 1982.

SCHÜLER, D. A poesia no Rio Grande do Sul. Porto Alegre: Mercado Aberto, 1987.

SILVA, J. P. d. A poesia nova e o Rio Grande. In: SILVA, João Pinto da. Vultos do meu caminho. Porto Alegre: Globo, 1927, p. 186-193.

VELLINHO, M. Letras da Província. 2. ed. rev. acrescentada. Porto Alegre: Globo, 1960 [1944].

ZILBERMAN, R. Literatura gaúcha: temas e figuras da ficção e da poesia do Rio Grande do Sul. Porto Alegre, L\&PM, 1985.

ZILBERMAN, R. A literatura no Rio Grande do Sul. Porto Alegre: Mercado Aberto, 1992a.

ZILBERMAN, R. Roteiro de uma literatura 
singular. Porto Alegre: EdUFRGS, $1992 b$.

Artigo enviado em: 15/05/2017

Aceite em: 28/07/2017 